\title{
Thermal annealing of radiation- damaged allanite-(Ce): Mechanical and structural properties
}

C.E. REISSNER ${ }^{1}$ M. REISSNER ${ }^{2}$ U. BISMAYER ${ }^{3}$ A. NAVROTSKY ${ }^{4}$ C. PAULMANN ${ }^{3,5}$ H. PÖLLMANN ${ }^{1}$ T. BEIRAU $^{1}$

${ }^{1}$ Institute of Geosciences and Geography,

Mineralogy/Geochemistry, Martin Luther University Halle-Wittenberg, 06120 Halle, Germany (correspondence: claudia.reissner@geo.uni-halle.de)

${ }^{2}$ Institute of Solid State Physics, TU Wien, 1040 Vienna, Austria

${ }^{3}$ Departement of Earth Sciences, University of Hamburg, 20146 Hamburg, Germany

${ }^{4}$ School of Molecular Sciences and Center for Materials of the Universe, Arizona State University, Tempe, Arizona 85287, USA

${ }^{5}$ HASYLAB, DESY, 22603 Hamburg, Germany

The mineral allanite-(Ce) with the ideal formula ${ }^{\mathrm{Al}}(\mathrm{Ca})^{\mathrm{A} 2}(\mathrm{REE})^{\mathrm{M} 1, \mathrm{M} 2}(\mathrm{Al}) 2_{2}^{\mathrm{M} 3}\left(\mathrm{Fe}^{2+}\right)\left[\mathrm{SiO}_{4}\right]\left[\mathrm{Si}_{2} \mathrm{O}_{7}\right] \mathrm{O}(\mathrm{OH})$ is a member of the epidote- supergroup [1] and can incorporate up to $5 \mathrm{wt} \% \mathrm{ThO}_{2}$. The incorporated thorium leads to structural damage through $\alpha$-decay, while thermal annealing can reestablish the structure. Allanite is an interesting example for actinide contaminated materials as structured $\mathrm{OH}^{-}$groups are assumed to act as a catalyst in the recrystallization process [2].

In this study different allanite-(Ce) samples with varying degrees of damage have been investigated. Combined results from nanoindentation, DSC/TG-MS, synchrotron singlecrystal X-ray diffraction and Mössbauer spectroscopic measurements reveal a detailed picture of the structural response to step-wise thermal annealing [3]. It is shown that the recrystallization process starts below $700 \mathrm{~K}$ and causes an increase in the mechanical properties (hardness and elastic modulus). The sample with the highest $\mathrm{OH}^{-}$content showed enhanced recrystallization behavior. Along with the loss of structural water, the iron oxidizes. A preferred iron position in the crystalline material could be determined [4].

[1] Bonazzi, Holtstam, Bindi, Nysten, Capitani (2009) Am Mineral 94:121-134 [2] Zhang, Salje, Malcherek, Bismayer, Groat (2000) Can Miner 38:119-130. [3] Reissner, Bismayer, Kern, Reissner, Park, Zhang, Ewing, Shelyug, Navrotsky, Paulmann, Škoda, Groat, Pöllmann, Beirau (2019) Phys Chem Mineral 46:921-933. [4] Reissner, Reissner, Kern, Pöllmann, Beirau (2020) Hyperf Interact 241:18 